\title{
Seramik Takviyeli Alüminyum Esaslı Metal Matrik Kompozitlerin Aşınma Özelliklerinin İncelenmesi
}

\author{
${ }^{1}$ İsmail Topcu, ${ }^{2}$ Mehmet Dikici, ${ }^{2}$ Cengiz İpek \\ ${ }^{1}$ Alanya Alaaddin Keykubat Üniversitesi, Mühendislik Fakültesi, Metalurji-Malzeme Müh. Bölümü, Alanya Antalya \\ ${ }^{2}$ Alanya Alaaddin Keykubat Üniversitesi, Mühendislik Fakültesi, İnşaat Müh. Bölümü, Alanya Antalya
}

Özet:

Alüminyum alaşımları muhteviyatları itibari ile, düşük yoğunluk iyi mukavemet özelliklerinden dolayı ileri teknmololjimalzemeleri olarak yaygın olarak kullanılmaktadır. Aluminyum ve alaşımlarının mekanik özellikleri, metal veya seramik bazlı takviye elemenları ile yeni metal matris kompozitleri oluşturulabilir. Takviye edilen parçacıklar ile yeni malzemelerin özellikleri büyük ölçüde iyileştirilebilir. Bu çalışma da toz metalurjisi karıştırma yöntemiyle Aluminyum matrisine ilave edilen bor karbürlerin (B4C) değişik sinterleme koşulları altında mikroyapı, yoğunluk ve aşınma direnci üzerine etkileri incelenmiştir. Atritor de mekanik karıştırma ile üretilen tozlar, soğuk izostatik pres kalıbı ile $400 \mathrm{MPa}$ basınç altında sıkıştırılarak silindirik kompozit numuneler elde edilmiştir. Üretilen numuneler, $600,625,640^{\circ} \mathrm{C}$ 'lerde 2 saatlik süre ile saf argon ortamında sinterlenmiş̧ir. Üretilen metal matris kompozitin aşınma davranışı pin-on-disk aşınma test cihazı kullanılarak incelendi. Uygulanan sinterleme sıcaklıklarının Al/ B4C alaşımları aşınma davranışları sabit yük ve sabit mesafe altında incelenmiştir. Uygulanan uygun koşullar altında B4C takviyesi kompozitlerin aşınma oranını iki dereceden fazla azaltabileceği görülmüştür. Elde edilmiş olan aşınma performansını takviye oranları ile ilişkilendiren çeşitli araştırmalar da yapılmıştır. Aluminyumun aşınma test sonuçları, B4C takviye oranlarının değişimi sonucunda aşınma tiplerinde farklılık olduğu ve aşınma direncini arttırdığı gözlenmiştir. Yapılan deneysel çalışmalarda aşınma direnci doğrudan ağırlıkça takviye edilen \% B4C oranları ile değiştiği ve artan takviye oranına bağlı olarak özellikle \% 15 B4C oranı ile daha çok arttı̆̆ gözlemlenmiştir.

Anahtar Kelimeler: Aşınma, B4C, toz metalurjisi

\section{Investigation of Wear Properties of Ceramic Reinforced Aluminum Based Metal Matrix Composites}

\begin{abstract}
:
Aluminum alloys are widely used as advanced monolithic materials due to their low strength, good strength properties. The mechanical properties of aluminum and its alloys, metal or ceramic based reinforcement elements and new metal matrix composites can be formed. The properties of reinforced particles and new materials can be greatly improved. In this study, effects of boron carbides (B4C) added to aluminum matrix on microstructure, density and wear resistance under different sintering conditions were investigated by powder metallurgy mixing method. Powder produced by mechanical agitation in the atritor was compacted under pressure of $400 \mathrm{MPa}$ with cold isostatic press die to obtain cylindrical composite specimens. The produced samples were sintered in pure argon atmosphere at $600,625,640{ }^{\circ} \mathrm{C}$ for 2 hours. The wear behavior of the produced metal matrix composite was studied using a pin-on-disk wear tester. $\mathrm{Al} / \mathrm{B} 4 \mathrm{C}$ alloys wear behaviors of the applied sintering temperatures were investigated under constant load and constant distance. It has been observed that $\mathrm{B} 4 \mathrm{C}$ reinforced composites under the appropriate conditions can reduce the wear rate by more than two orders of magnitude. Various investigations have been carried out which relate the obtained wear performance to reinforcement rates. Aluminum wear test results have been observed to vary in wear types as a result of changing $\mathrm{B} 4 \mathrm{C}$ reinforcement ratios and to increase wear resistance. In the experimental studies carried out, it was observed that the wear resistance increased with the ratio of B4C directly reinforced by weight, and especially increased by $15 \% \mathrm{~B} 4 \mathrm{C}$ due to the increased reinforcement ratio.
\end{abstract}

Key words: Wear, B4C, powder metallurgy

*Alanya alaaddin Keykubat Üniversitesi,Mühendislik mFakültesi, Metalurji \&Malzeme mühendisliği Bölümü, 07450, Alanya-Antalya-TÜRKIYE E-mail: ismail.topcu@alanya.edu.tr, Tel: 902425106120 Fax: +90 2425106124 


\section{Giriş}

Toz metalurjisi (T/M) tedarik edilmiş olan farklı oranlardaki tozları mekanik olarak karıştırmak suretiyle spesifik ve birebir ölçülerde malzeme üretmek için kullanılan bir üretim prosesidir. $\mathrm{Bu}$ sürec, son ölçülerde çok basit veya daha complex parçalar imal etmede düşük maliyetinden dolayı Komplex sekillei üreünler üretmek için vazgeçilmez bir yöntem çeşididir. Toz metalurjisi yönteminde bir çok farklı malzeme kullanılmaktadır. Seramik matrisli kompozit malzemeler $(\mathrm{CMCM})$ ve Metal matrisli kompozitler (MMC) bunlardan bazılarıdır. MMC ler en az bir metal ile bunalara eklenecek takviye elementinden meydana gelmektedir. Yalnız bir takviye elemanı ile ihtiyacı giderilemeyen beklentilere ve istenen özelliklere sahip olmak için genellikle lif, intermetallik parçacıklar, bileşikler, oksitler, karbürler veya nitrürler gibi takviye malzemelerine ihtiyaç duyulur [1]. Halihazırda MMC sinterlemesi ile bir çok farklı takviye materyali kullanılarak MMC kompozit üretimi daha elverişli hale gelmiştir.MMC'nin geliştirilmesinin ardındaki en önemli etken iyi mekanik ve fiziksel özelliklerin yanısıra takviye ile artırılmış olan yüksek sıcaklık yetenekleri olmuştur [2]. Elde edilmiş iyi mekanik özelliklerin yanısıra, termal özellikler (termalgenleşme katsayısı) ve aşınma davranışları gibi temel özellikler seramik takviyesiyle önemli oranda geliştirilmiştir [3]. Bor karbür ve türevlerinin çok iyi mekanik ve fiziksel özelliklere sahip olması yatmaktadır. Sertli değerleri kıyaslandığında elmastan sonra en sert malzeme c-BN' dir. Bu özellik ile birlikte diğer özellikleride göz önüne alındığında bu malzeme vazgeçilmez olmaktadır [4].

MMK'lara yapılan ilave elementler ana matrik kompozitlerin ihtiyaç duyulan özelliklerini geliştirerek daha yaygın uygulama alanları yaratmaktadır. Bu malzemelerin söz konusu özellikleri iyileştirilirken takviye elemanlarının ilave miktarları ve ilave elamanların fiziksel özellikleride önem arz etmektedir. Bu pararlellikte uygun takviye ve yapılan boyut optimizasyonu geliştirilen kompozit malzemede üstünlük sağlayacak çeşitli avantajlar sunar [5]. Yoğunluğu düşük, iyi mekanik özelliklere sahip malzemelere olan gereksinim ilerleyen zamanlarda otomobil ve hava araçlarının üretilmesinden bu yana bilinmektedir. Kullanılmakta olan araçlarda güvenlik bu malzemelerin uygun mukavemet ve sertlik aralıklarına dolayısı ile gerekli olan malzeme miktarı boyutlarına bağlıdır. Dolayısı dizayn edilecek araçlarda kullanılan malzeme miktarıda aracın toplam kütlesini etkileyecektir. Daha iyi mekanik özelliklere sahip amlzemden imal edilecek daha düşük kütleli uçak ve otomobillerde, yük artışına rağmen ve yakıt verimliliğinin iyileştirilmesi gibi birçok avantajlar sağlamaktadır [6].

Metal matris kompozitler, çok iyi mekanik özelliklerinden (E modül, Çekme dayanımı, Aşınam davranıları) dolayı geleneksel malzemelere kıyasla daha çok tercih edilmektedir. Bir çok akademik alüminyum elementini kullanaral $\mathrm{Al} / \mathrm{MMC}$ lerin farklı koşullar altında farklı ( $\mathrm{SiC}, \mathrm{Al} 2 \mathrm{O} 3$, TiC ve B4C) takviye elemnları kullanılarak aşınma davranışlarını incelemiştir [4]. Aşınma davranışı üç faklı şekilde değerlendirilir. Sırası ile şiddetli aşınma, hafif aşınma ve başlangıç aşınma safhalarıdır. Söz konusu durum gerçekleşirken prosesin hangi aşamada gerçekleştiği, ortam sıcaklığı, kritik uygulama sıcaklığı ve aşınan malzeme miktarı (Aşınma oranı) değişiklikler göstermektedir [7,8].

Aşınma, üretilmiş olup ve deneye tabi tutulan malzeme yüzeyinden ayrılmaların gerçekleşmesi ile meydana gelen yüzeyin fiziksel bir değişimdir. Testler belli ağrlıklar ve tatbik süresi boyunca numunelerin fiziksel boyutlarında meydana gelen değişim ile ölçülür. Test düzeneğindeki büyün mekanik bileşenlerin etkileşiminden dolayı bir miktar yıpranma meydana gelir [9]. Aluminyum 
matriks kompozit malzemelerin aşınma davranışları, takviye edilen parçaçıkların, büyüklüğüne, oranına ve matrise iyi bağlanıp bağlanmaması belirleyici etkendir. Eğer bu detaylar optimize edilirse üretilecek kompozitin aşınma direnci artar [10].

$\mathrm{Bu}$ çalışmanın amacı, üç farklı oranla takviye edilen B4C ilavelerinin Aluminyum matrisi aşınma özelliklerini ne şekilde etkileyeceğini incelemektir. Sırası ile mikroyapı için metalografik incelemeler yapılmıştır. Al/B4C 'li sinterlenmiş her kompozit numunede, kuru disk üzerinde ve kuru disk ile aşınma deneyleri gerçekleştirilmiştir. ÖncesindeTaramalı elektron mikroskobu (SEM), X-ray ile karakterize edildi. Mikrosertlik ve arşimet yoğunluk testleri yapılarak bu numunelerin mekanik özellikleri incelenmiştir.

\section{Malzeme ve Methot}

\subsection{Numune üretimi ve hazırlama teknikleri}

Bu çalışmada, boyutları ortalama $10 \mu$ m'lik ağırlıcça \% 5 -15'lik B4C toz partikülleri kullanılarak saf alüminyum ile bir araya getirilerek üretilmiş olan farklı oranlardaki Al/B4C kompozitleri kullanılmıştır. Üretim süreci toz metalürjisi (TM) yöntemleri uygulanarak gerçekleştirilmiştir. Amerikan menşeli aluminyum tozları ana matris malzemesi olarak kullanılmıştır. Alfa Aesar, Johnson Matthey GmbH \& Co. Firmasından temin edilen bu tozlar yüksek saflıkta (\%99,99 saflık), 2,699 g / cm3 yoğunluk ve $10 \mu \mathrm{m}$ nominal büyüklügüne sahip atomize saf aluminyum(Al) tozlarıdır. Matrisi güçlendirici takviye elemanı olarkta aynı yine ameriakan malı ve aynı (Alfa Aesar, Johnson Matthey GmbH \& Co. KG) firma tarafında üretilen B4C tozları kullanılmıştır. Bu tozların yoğunluğu 2,52 $\mathrm{g} / \mathrm{cm} 3$ ve ortalama $10-30 \mu$ boyutlarındadır.

\subsection{Karakterizasyon}

Malzeme karekterizasyonu ve mikroyapı analizlerinde malzeme biliminde kullanılan en yaygın ve etkili görüntüleme yöntemlerinden biri Scanning Electron Microscope (SEM) cihazı ile yapılan çalışmalardır. Bu yöntemde, numune yüzeyi yüksek enerjili bir elektron demeti ile taranarak görüntüler elde edilir. TM yöntemi ile Üretilerek sinterlenmişolan kompozit malzemelerin morfojileri ve mikroyapıları SEM de (JEOL Ltd., JSM5910LV) incelenmiştir. Yüksek saflıktaki Alüminyum ve takviye B4C tozuna sahip farklı fazların tanımlanabilmesi için de Rigaku X Ray difraktometresi kullanılmıştır. Bu tarama $\mathrm{Cu} / \mathrm{K} \alpha$ radyasyonu kullanılarak, $2^{\circ}$ lik bir ışın açısı ile, $10-85^{\circ}$ aralığında, $0.02^{\circ}$ atış ile incelendi. SEM incelemsi yapılırken aynı zamanda noktasal olarak 133-eV çözünürlüğe sahip Enerji Dağılımlı Spektrometre (EDS) (OXFORD Industries INCAxsight 7274) cihazı kullanılarak faz taraması yapıldı.

\subsection{Al/B4C Metal Matriks Kompozitlerinin Üretimi}

Toz Metalürjisi tekniği kullanılarak ağırlıkça farklı (\%5-15) oranlara sahip Al/B4C kompozitleri üretilmiştir. Üretim esnasında bağlayıcı olarak \%1 acrowax kullanılmıştır. Karıştırma işlemi mekanik alaşımlama yönteminin uygulandığı su soğutmalı ile atritör milinde etil alkol ortamında yaklaşık olarak 7.5 saatte gerçekleşti. Üretimi gerçekleştirilen kompozit tozları içerisine ağırlığın 1:6 oranında $10 \mathrm{~mm}$ paslanmaz bilya konularak $400 \mathrm{rpm}$ devir hızında işlem sürdürüldü. Karıştırma işlemi sonunda kurutma işlemi için etüvde 50 oC de 4 saat bekletildikten sonar farklı elek sistemi kullanılarak ayrıştırma işlemi gerçekleştirildi. Ayrıştırılan Al/B4C kompozit tozları literatür e parallel olarak soğuk izostatik basma (SİP) $350 \mathrm{MPa}$ ile preslendi. Preslenmiş olarak elde edilen 
bütün peletler yatay tüp firında yüksek saflıktaki saf argon ortamında $75 \mathrm{dk}$. boyunca boyunca 3 farklı sicaklıkta $(600,615,640$ 0C lerde sinterlendi. Bu sıcaklıkları seçmemizdeki amaç Aluminyumun 590-640 0C aralıklarında gerçekleşen faz dönüşümleridir. $\mathrm{Bu}$ sıcaklıklarda gerçekleşecek faz dönüşümleri ile daha iyi mekanik özellikler elde etmek. Al/B4C faz diyagramında faz geçiş sıcaklıkları, farklı sıcaklık ve oranlarda ortaya çıkabilecek fazlar Şekil'1 deki faz diyagramında görülmektedir [11].

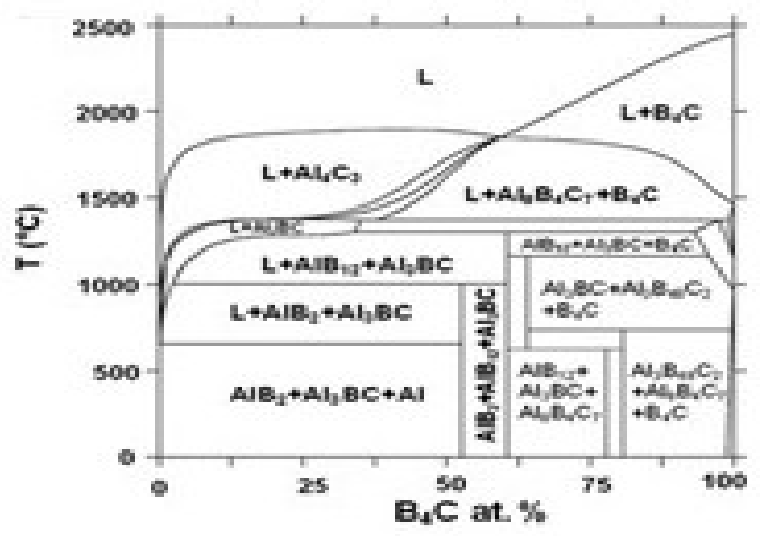

Şekil 1. Al-B4C faz geçiş diyagramı; Al-B4C isohips faz diyagramı [12].

\subsection{Yoğunluk ve Sertlik Deneyleri}

Üretilen Al/B4C kompozit malzemelerinin öncelikle yoğunluk testleri yapıldı. Bu testler literatürde yoğunlukla kullanılan Archimedes yöntemi ile ölçülmüş̧tür (Switzerland- Presciva XB 320 M). Yapılan yoğunluk testlerinin ardından metalografik olarak hazırlanan numuneler (FM-700, Future Tech Corp.) mikro test cihazında HV yöntemi ile (Vickers 1360500 gr yük) gerçekleştirildi.

\subsection{Metalografik Inceleme}

Toz metalurjisi yöntemi ile üretilmiş olan bütün numuneler sinterleme prosesi sonucunda metalografik incelemler için sirası ile X240, X500, X800 ve X1000 SiC zımpara kağıtları ile hazırland1. Zımparalanan numunelerdaha sonar çuhada Alümina (Al2O3) pasta ile düşük devirlerde parlatıldı. Parlatıldıktan sonar dağlamaya hazır numuneler dağlama prosesinde kroll reaktifi (6 mL HF, $200 \mathrm{~mL} \mathrm{H2O}$ içinde $12 \mathrm{~mL}$ HNO3) ile dağlanarak mikroyapıları görüntü yönündeki kesitlerden SEM cihazında incelendi.

\subsection{Aşınma Testi}

Aşınma testleri, laboratuar şartlarında kuru ortamda gerçekleştirildi. Mekanizma olarak 65 HRC sertlik değerine sahip takım çeliğinden imal edilmiş sürekli dönen aşındırıcı plakanın olduğu standart bir pin-on-disk aşınma cihazında gerçekleştirildi. Bu test için numuneler $\varnothing 10 \times 10 \mathrm{~mm}$ boyutlarında ve aşınma yüzeyide $0.159 \mathrm{~nm}$ Ra'lık bir pürüzlüğe kadar parlatıldı. Aşınma testi, bütün oranlardaki her numune için tekrarlanabilirliği sağlamak için üç deneme ile gerçekleştirildi. Disk yüzeyi pürüzlülük sağlamak için (0.832 um Ra) taşlanmıştır. Bütün testler sırasıyla kayma hızı, kayma mesafesi ve uygulanan yük, $1.03 \mathrm{~m} / \mathrm{s}, 3000 \mathrm{~m}$ ve $1 \mathrm{Kg}$ 'da sabit tutulmuştur. Teste tabi tutulacak numuneler etanol ile temizlenmiş ve ağırlık kaybı ölçümleri için testten önce \pm 0.0001 gram hassasiyette sahip terazide ölçümler gerçekleştirilmiştir. Yapılan ağırlık ölçümleri sonunda 
tekrardan etanol ile temizlenen numuneler test düzeneğine yerleştirilmişri. Deney sonuçlarının iyi alınabilmesi için her numuneye aynı işlem uygulanmış ve her numune 3 defa teste tabi tutulmuştur [13]. Aşınan numene yüzey incelemeleri SEM'de gerçekleştirlimiştir.

\section{Sonuçlar ve Değerlendirmeler}

Aluminyum ve bor karbür tozları tam küresel şekilli olmayıp tane boyut dağılımı ortalama $10 \mu$ civarındadır. Numune hazırlama işlemi sonrası üretilen bütün kompozit numuneler için aynı büyütme oranı kullanılmıştır. A1/B4C kompozit numunelerin düz kesitlerden elde edilmiş olan SEM görüntüleri de Şekil 2'de görülebilir. Şekiller de takviye oranına bağlı olarak özellikle düşük takviye oranına sahip numuneler de Al'un B4C ile homojen dağılımı ve Aluminyumun B4C ile yapmış olduğu fazlar net olarak görülmektedir. Ayrıca yapıda gri ve daha koyu alanlarda mevcuttur. Gri alanlar oluşan karbür yapılarını nispeten daha koyu bölgelerde artan B4C miktarı ile birlikte yer yer porozitenin yoğun olduğu bölgeye de tekabul etmektedir. Özellikle \%15 B4C oranına sahip numunede yoğunluk ve sertlik değerlerinin artan sinterleme sıcaklığı ile önemli oranda artmıştır. Görüldüğü gibi sadece gri alanlarda Al3BC yapıları bulunmaktadır. Gri alan, artan B4C oranına bağlı olarak optimum olarak artmıştır.

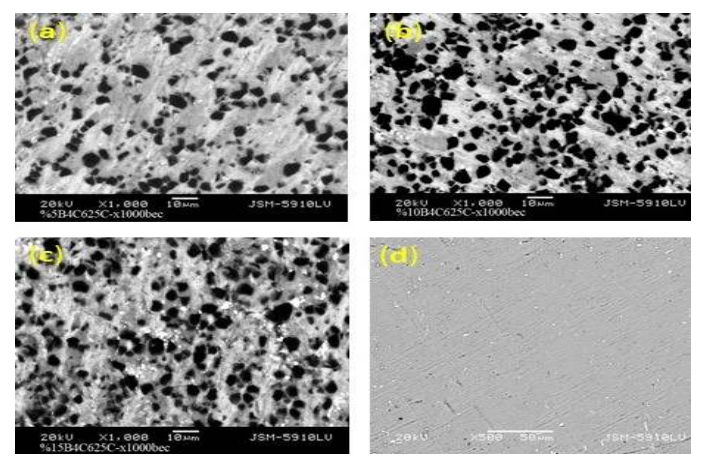

Şekil 2. $650^{\circ} \mathrm{C}$ de sinterlenmil Al/B4C kompozitleri, (a)\%5 Al/ B4C takviyeli MMK, (b) \% $10 \mathrm{Al} / \mathrm{B} 4 \mathrm{C}$ takviyeli MMK, (c) \%15 Al/ B4C takviyeli MMK, takviyeli malzemelerin SEM fotoğrafları

XRD çalışmalarının amacı Al/B4C kompozitlerinde çeşitli faz ve reaksiyon ürünlerini incelemektir. Şekil 3'te de görüleceği üzere Saf aluminyum ve B4C tozlarına ait yapılan xrd karekterizasyon incelemedesinde aluminyuma tozuna ait ana pik 38.70 ikincil pik ise 44.80 görülmüş ve aynı şekilde B4C'ye ait pikler de sırasıyla 28.90 ve 38.40 ler de ortaya çıkmıştır.
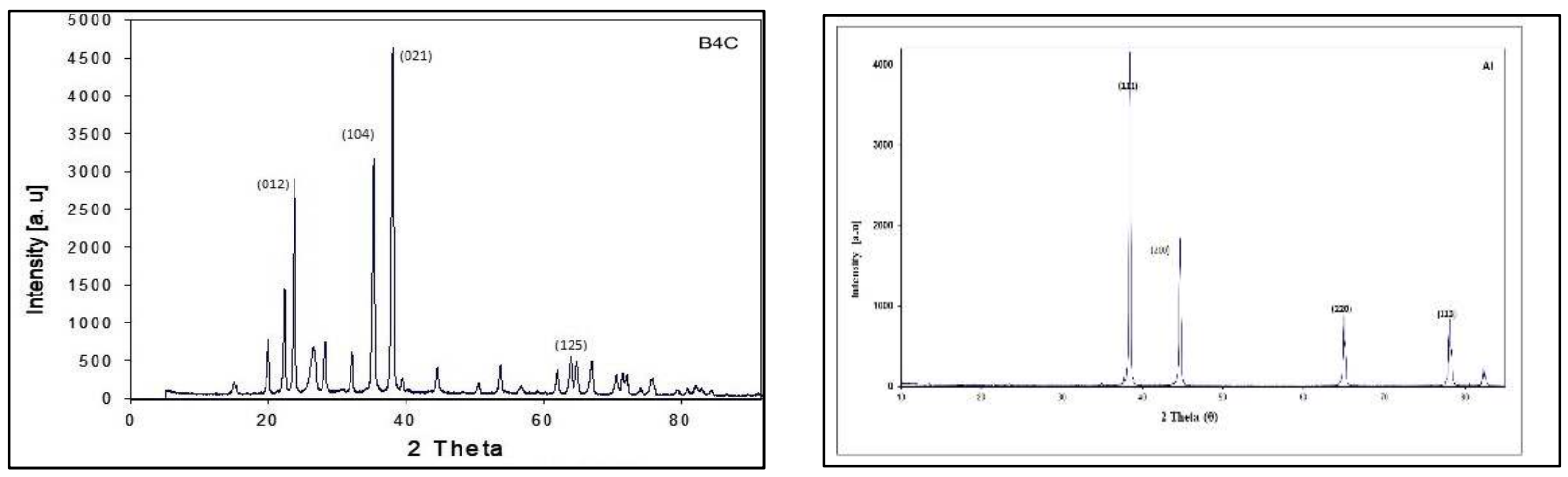
Şekil 3. Saf Aluminyum ve B4C tozlarının XRD analizi

XRD paterninin sonuçları $\mathrm{Al}, \mathrm{B} 4 \mathrm{C}, \mathrm{Al} 2 \mathrm{~B}$ ve $\mathrm{A} 13 \mathrm{BC}$ 'nin yoğunluk piklerini göstermektedir (Şekil4). AlB2 ve Al3BC fazları, ana matris aluminyum ve takviye B4C arasındaki arayüzde oluşmuştur. AlB2 fazının varlığı nispeten azdır [14]. XRD sonuçları, diğer takviye oranlarına nazaran 15\% Al/B4C kompoziti daha homojen karışım göstermektedir. Takviyedeki artışla kompozitin pik şiddetietini artmaktadır.B4C takviyesi sonucunda \%15 ağırlıkça en yüksek takviye oranlı $\mathrm{Al} / \mathrm{B} 4 \mathrm{C}$ ile üretilen kompozit malzemenin xrd karekterizasyon incelemedesinde aluminyum metal tozları (111) ve (200) düzlemlerinde, B4C seramik tozları ise (104) ve (021) düzlemlerinde en yüksek pik şiddetlerini göstermektedirler. Al/B4C kompozit numunesinin xrd analizinde takviye B4C oranının artması ile B4C piklerine ait hem pik şidddeti hemde pik alanlarında gözle görülür artış olduğu çok açık ve net olarak görülmektedir [15].

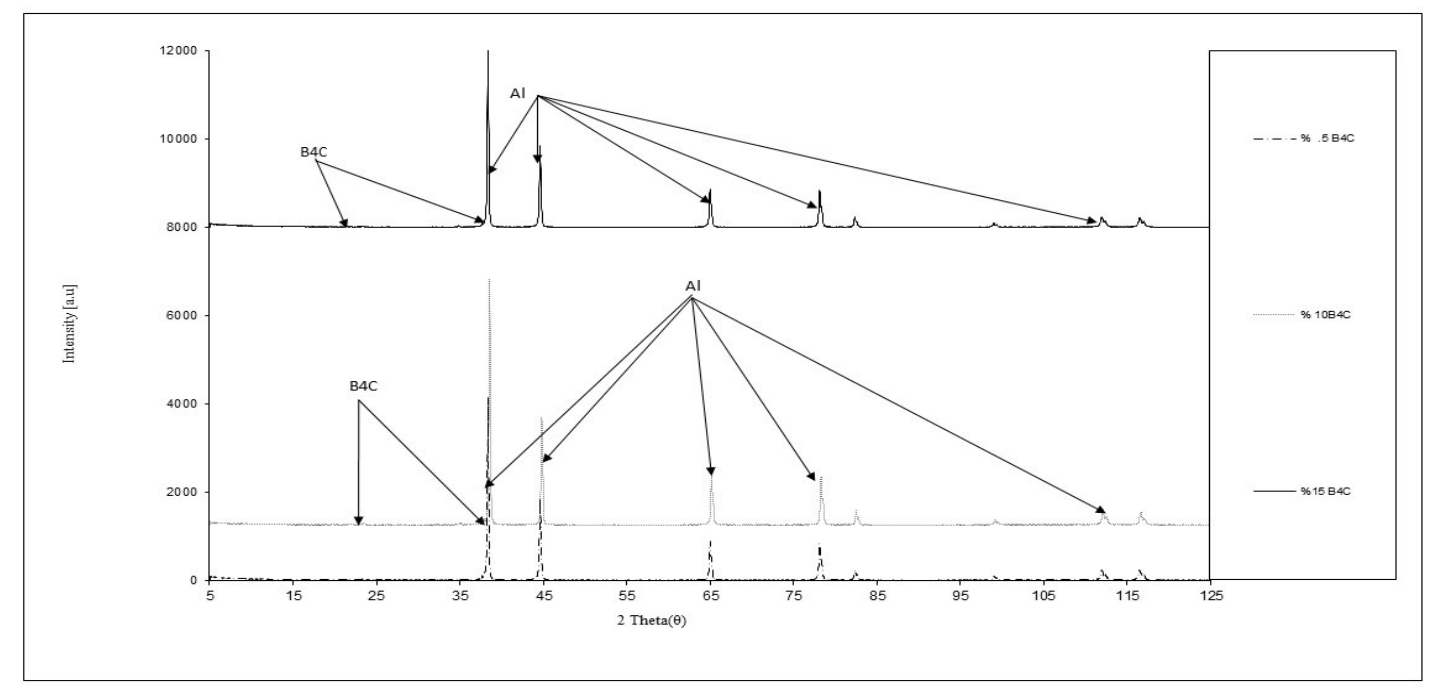

Şekil 4. \% 5-15 oranında B4C ile takviye edilmiş Al/B4C kompozitinin XRD analizi

Şekil 4 te görüleceği, en şiddetli pik Al/B4C nin \%15 lik takviye oranında olan numunede elde edilmiştir. Üretilmiş olan $\mathrm{Al} / \mathrm{B} 4 \mathrm{C}$ numunelerinin yoğunlukları ölçülüp literatürle uyumlu olduğu ve $\% 95$ ile \% 97,5 oranları arasında kaldığı gözlemlenmiştir. Bu oran farkının başlıca nedeni B4C nin yoğunluğunun düşük olması, B4C'nin oran olarak artması ve karşılaşılan porozite miktarıdır. Yoğunluk hesaplamaları 1 numaralı eşitlikte sunulmuştur.

$$
\mathrm{C}_{\mathrm{R}}=\mathrm{V}_{\mathrm{L}} / \mathrm{V}_{\mathrm{C}}=\rho_{\mathrm{G}} / \rho_{\mathrm{A}}
$$

Eş. 1 ifadelerinde; $\mathrm{VL}=$ gevşsek tozun hacmi, $\mathrm{VC}=$ sıkıştırılmış tozun hacmi, $\rho \mathrm{G}=$ ham yoğunluk ve $\rho A=$ görünür yoğunluktur.

$\mathrm{Al} / \mathrm{B} 4 \mathrm{C}$ kompozit numunelerinin en düşük yoğunluğu ağırlıkça en yüksek B4C oranına sahip olan \%15 içerikli numunede hesaplanmıştır. Farklı oranlarla takviye edilerek üretilen kompozitlerin yoğunluk değerleri Şekil 5'de gösterilmiştir. 


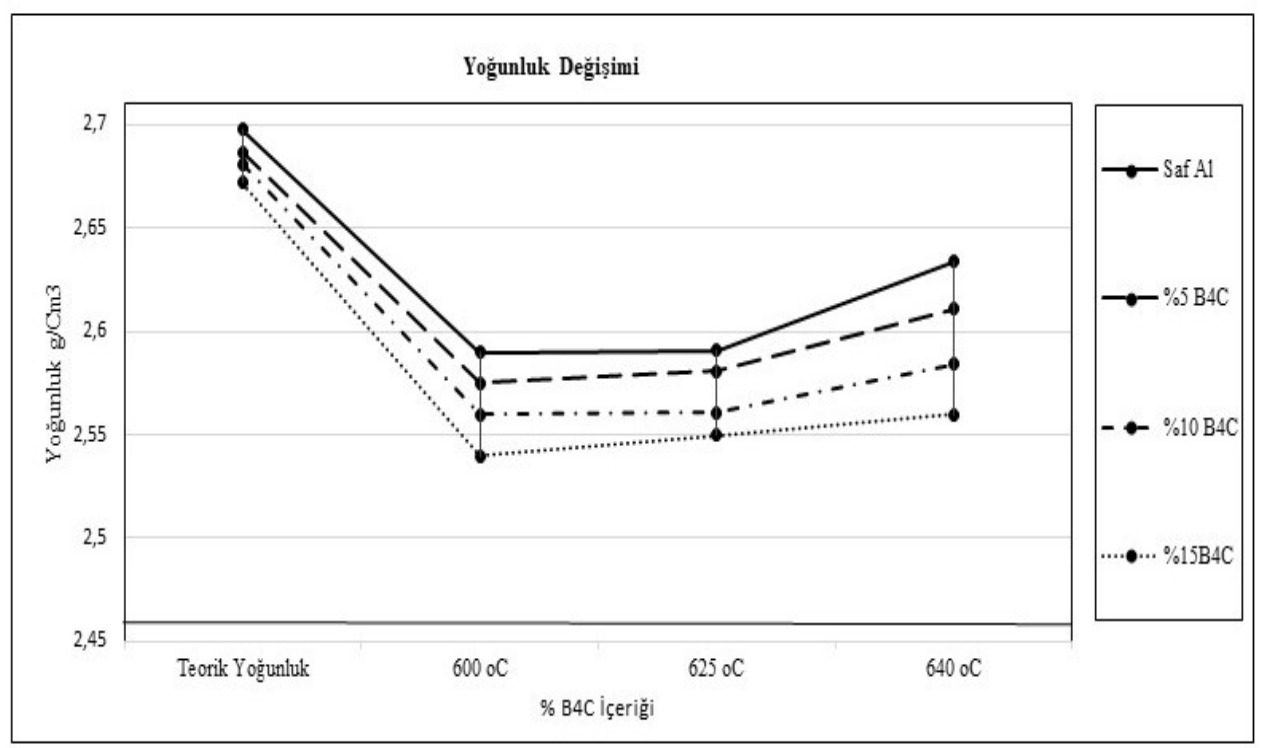

Şekil 5. \% 5-15 oranlarında B4C ile takviye edilerek üretlen numunelerin yoğunluk değerleri.

Üretilen numunelerin yoğunluğunun, \% 5-15 farklı B4C içerikli üretilem kompozit numunelerin artan \% B4C oranları ile düştüğü fakat kendi içlerinde de sinterleme sıcaklığına bağlı olarak arttığı görülmektedir. Deney sonucunda üretilen numunelerden beklenti uygulanan yüksek sinterleme sıcaklığı ve artan B4C oranı ile yoğunluğun literatürle parelel bir şekilde $(\% 97,5)$ istenilen seviyeye ulaşmasıdır [17]. Üretilmiş ve metalografik olarak hazırlanmış olan kompozit numunelere sertlik testi yapıldı. Bu testte baskılayıc izin hem matris hem de takviye malzemesini kapsadığından emin olmak için sık aralıklarla $(150 \mu) 10$ ardışı ölçüm yapıdı ve çıkan değerlerin ortalaması hesaplanarak sonuçlar elde edildi. Elde edilmiş olan sertlik değerleri Al/B4C kompozitlerinin ortalama sertliğini temsil etmektedir. Sertlik ölçümleri Şekil 8'de verilmiştir.

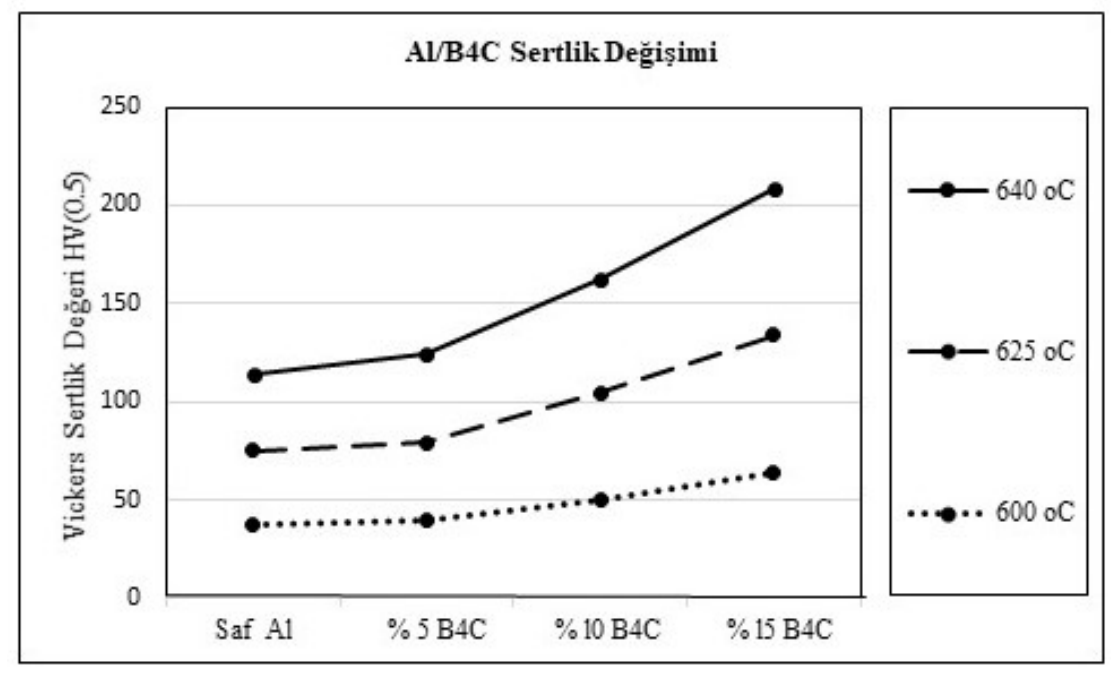

Şekil 6. \% 5-15 oranların da B4C ile takviye edilerek üretlen Al/ B4C kompozit numunelerinin sertlik 
B4C nin ağırlıç̧a yüzdesinin artması, bileşiğin sertliğini arttırmıştır. Farklı takviye oranlarına sahip numunelerin ölçülen sertlik ölçümlerinde farklılık gözlemlenmiştir. Kompozit malzemelerin sertlik değerleri takviye B4C'lerin aluminyum ile meydana getirmiş oldukları (A1B2, A13BC) fazları nedeni ile atırmıştır., buna karşılık yer yer daha düşük sertlik değerleri de elde edilmiş olup ana matriste artan B4C miktarının yanısıra saf al matrisine denk gelmesi ile açıklanabilmektedir. [18]. Bazı araştırmacılar artan takviye B4C oranı ile birlikte malzemede mukavemet artışı meydana geldiğini belirtmişlerdir. Buna neden olarakta yapının karbon içeriği ile sertlik değerlerinin lineer olarak arttığını savunmuşlardır. Karbürize edilmiş tabaka, diğer numunelere kıyasla daha fazla yüzey gerilimlerine sahip olmuş ve sertlik artışı sağlamaktadır [19]. Söz konusu kabulü dikkate alarak; bu çalışmada, aşınmaya maruz bırakılan yüzey tabakasında oluşan Aluminyum Borür (AlB2) ve Aluminyum Borkarbür (A13BC) yapıları aşınma direncinde artışa neden olmuştur.

Aynı şekilde üretilmiş ve yüzeyleri metalografik olarak hazırlanmış olan kompozit numuneler aşınma testine tabi tutuldu. Farklı aşınma hem katedilen yol hemde ağırlığı kaybı olarak hesaplandı. Aşınma oranı aşağıdaki eşitlik kullanılarak hesaplanmıştır.

$$
W_{S}=\frac{\mathrm{D} m}{\mathrm{q} \cdot \mathrm{L} \cdot F_{N}} 10^{9}
$$

Eş. 2 ifadelerinde, Ws: Aşınma oranı, mm3 / Nm, Dm: $\mathrm{N}$ devirlerinin aşınma testi sırasında test örneklerinin kütle kayb1, g, q: Test materyallerinin yoğunluğu, g / cm3. L: Toplam kayma mesafesi, $\mathrm{m}$ ve F: Pimin üzerindeki normal kuvvet, $\mathrm{N}$.

Toplam kayma mesafesi otomatik kayıt cihazında izlenmiştir. Tüm örneklerin aşınmış yüzeyleri SEM kullanılarak incelendi. Aşınma testinde sabit ağırlık olarak $1 \mathrm{~kg}$ kullanıldı. Aşınma şartları Şekil 9'da gösterildiği gibi, üç farklı sintereleme sıcaklığı ve üç farklı kompozisyonla yapılmıştır. Yapılan çalışmada ağırlık kaybı, aşınma direnci ve aşınma oranları dikkate alınarak değerlendirme yapılmıştır [21].
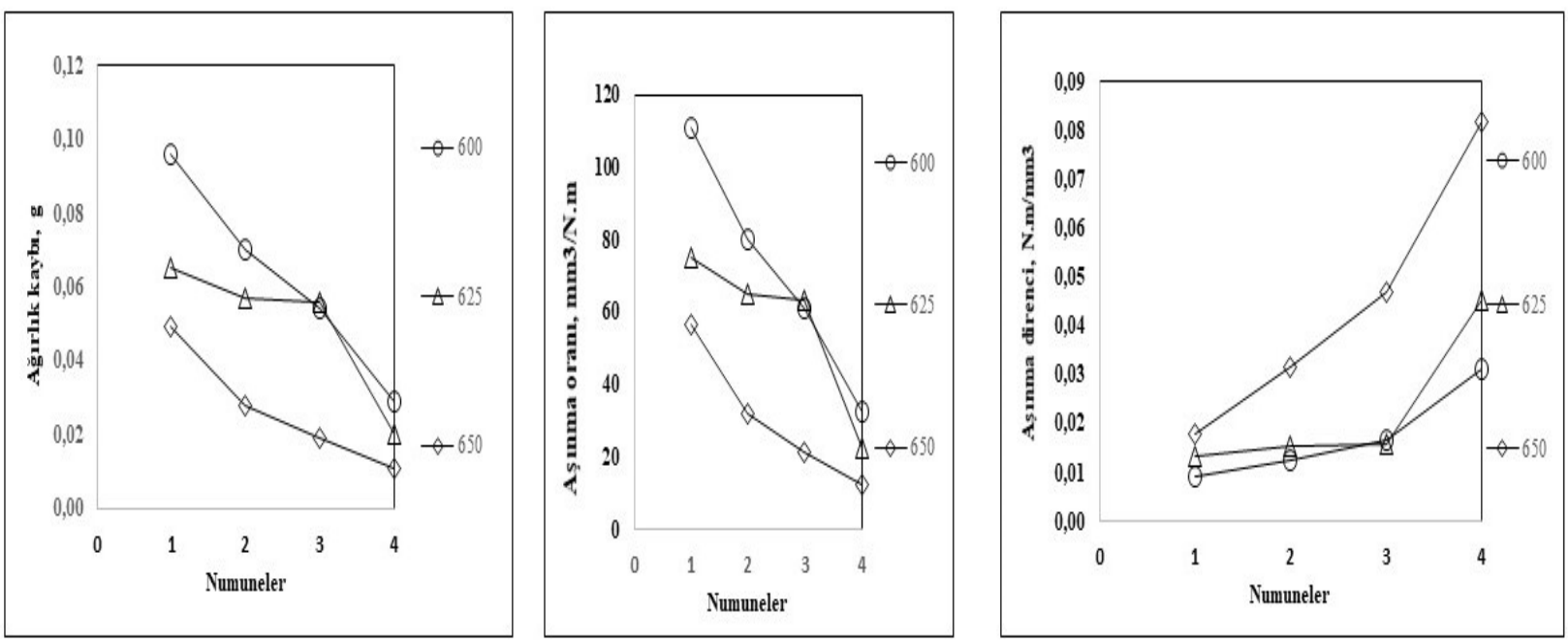

Şekil 7. Aluminyum ve (\%5-15 ) Al/B4C kompozitlerin aşınma test sonuçları a) Aşınma kaybı, b) Aşınma direnci, c) Aşınma oranı

Tatbik edilen test yükü $1 \mathrm{~kg}$ sabit olduğu için, görülen kütle kayıplarında, kompozitte artan \% B4C oranı ile aşınma oranının azaldığı ve kayma mesafesinin artması ile de aşınma kaybı artmış buna 
karşılık aşınma oranı azalmıştır. Özellikle, saf Aluminyum ile düşük takviye oranlı ilk kompozit (\% 5 B4C) numunenin aşınma hiç de iyi olmamasına karşın, takviye miktarı arttırılan diğer numunelerin (\% 10-15 B4C) aşınma kaybının gözle görülür biçimde azaldığı gözlemlenmiştir. İyi aşınma direnci, sert A13BC fazları ve kompozit içerisindeki B4C'lerin varlığına bağlanabilir. Kompozitin aşınma direncinin artması yapıdaki sert A13BC fazının varlığı ile açıklanabilmektedir. Yapılan bu testler sırasında yapıda bulunan sert A12B ve A13BC arayüz fazları kırılmayı zorlaştırarark mukavametin artmasına yol açar. Bundan dolayı takviye elemanı ile ana matris metali arasındaki bağ yapısı güçlenerek aşınma direncine kattkı sağlar [22].Kuru sürtünme şartlarında uygulanan $1 \mathrm{~kg}$ yük ile test edilen aşınmış numune yüzeylerinin görüntüleri Şekil 9 (a) $\% 5$ B4C ve 10 (b)\% 15 B4C görülmektedir.
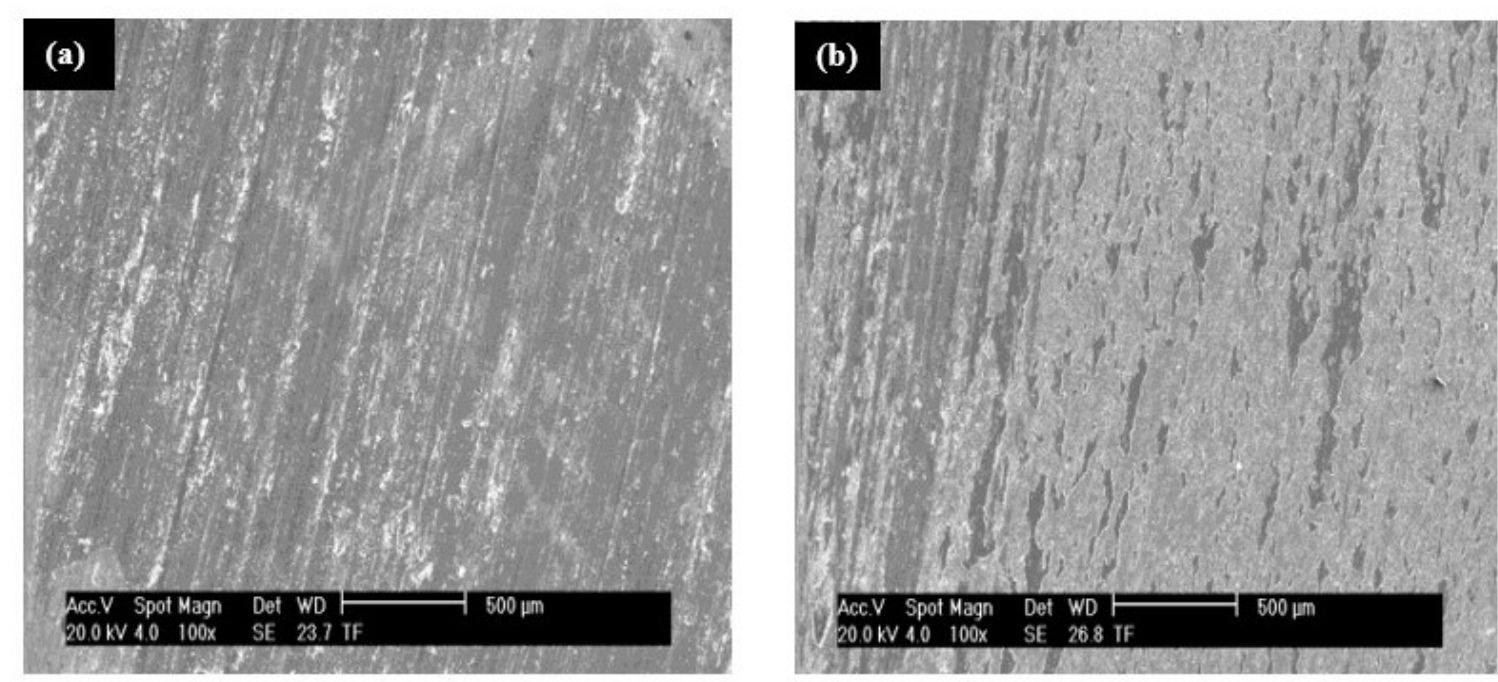

Şekil 8. Farkllı oranlardaki Al/B4C kompozitlerin aşınmış yüzeyleri; (a) \%5 B4C , (b) \%15 B4C

Tatbik edilen sabit yük farklı oranlardaki kompozitlerde (Şekil 10 (a) ve (b)), artan B4C'lerin yapışkanlı aşınmanın mekanizmasının ilerlemesini önlediğini kanıtlamaktadır. Söz konusu durum ana matris ve takviye elemanı arasındaki güçlü arayüzey bağlanması önermesini desteklemektedir. $\mathrm{Bu}$ çalışmanın sonuçları, yapılmış olan benzer çalışmalr ile paralellik arz etmektedir [23]. 5 \% B4C takviyeli malzemelerde yapışkanlı aşınma meydana gelmiş olup, \% 10 ve 15 takviyeli kompozitlerde yapışkanlı aşınma mekanizmasının değiştiği ilgili literatür çalışması ile desteklenmiştir. Bundan dolayı yüksek sertliğe sahip \% 15 Al/B4C kompozitleri aynı şekilde en yüksek aşınma direncine ulaşılmıştır. Beklendiği gibi, B4C takviyeleri ile üretilen AMMK'lerin aşınma direncini ve sürtünme özelliklerini iyileştirmede etkili olmuştur. Literatürde yapılan çalışmalar incelendiğinde düşük takviye miktarlı kompozitlerin neden daha düşük aşınma direncine sahip olduğu buna karşın artan takviye miktarı ile neden arttı̆̆ çok net bir şekilde açıklanmıştır.

\section{Tartışmalar}

-Bu çalışmada, farklı oranlarda karbon nanotüp takviye edilerek üretilmiş olan $\mathrm{Al} / \mathrm{B} 4 \mathrm{C}$ metal matris kompozitlerin yoğunluğu, sertliği, mikroyapısı ve aşınma özellikleri incelenmiştir. Elde edilen bulgular; farklı takviye oranlı kompozitlerin yoğunluğunun teorik yoğunluğa yaklaştığı ve 
bütün kompozitlerde artan \% B4C oranı ile istenen seviyelere (\% 96 - 97,5) ulaşmıştır. -Atritörde $60 \mathrm{dk}$. mekanik olarak karıştırılan kompozitlerden \%15'lik Al/B4C kompozitine ait XRD analizi sonucunda farklı $2 \theta$ açılarında ortaya çıkan piklerin rombohedral yapıya sahip B4C'ye ait olduğu belirlenmiş ve artan B4C takviyesi ile kompozitin ana pik alanında ve şiddetinde artışa meydana gelmiştir.

-Mikroyapı incelemelerinde takviye B4C tozlarının alümünyum matris içerisinde homojen dağıldığı, belirli bölgelerde aglomerasyon olmadığı fakat kısmide olsa porpzite görüldüğü tesbit edilmiştir.

-A1/B4C kompozitinde takviye miktarının (\%15 e kadar) artması ve yüksek sinterleme $\left(640{ }^{\circ} \mathrm{C}\right)$ sıcaklığının etkisi ile metal matriksli kompozitin sertliğini artmıştır.

-Sabit yükte $1 \mathrm{~kg}$ da kuru aşınma testinde ağırlık kaybı, aşınma direnci ve aşınma oranı takviye oranları ve yüksek sinterleme sıcaklıklarının etkisi ile ağırlık kayıplarında ve aşınma oranlarında azalma buna karşılık aşınma direncinde ise iyileşme meydana gelmiştir. Aşınma direncindeki iyileşme ana matris içerisinde oluşan A12BC fazından kaynaklanmaktadır. Literatürde yapılmış çalışmalara da refere edilerek yapılan aşınma testinde, takviye edilen B4C'lerin aşınma direnci üzerinde olumlu bir etkiye neden olduğu ve aşınma direncini iyileştirdiği düşünülmektedir.

\section{Teşekkür}

Bu çalışma, Marmara Üniversitesi Bilimsel Araştırma Projesi Programı (FEN-K-070317-0107) tarafından desteklenmiştir.

\section{Kaynaklar}

[1] Lee, K.B., Sim H.S.; Cho, S.Y.; Kwon, H.; Reaction Productsof Al- Mg/B4 Composite Fabricated by Pressure less Infiltration Technique, Materials Science and Engineering,2001, 227-234.

[2] German, R,M., Powder Metallurgy and Particulate Materials Processing, Princeton USA, (2005)

[3] Topcu İ., Karbon Nanotüp Takviyeli Aluminyum Matriksli AlMg/KNT Kompozitlerinin Mekanik Davranışlarının İncelenmesi, Journal of Graduate School of Natural and Applied Sciences, 2018,4:1,99-109.

[4] J.Udaya Prakash J., Ananth S., Sivakumar G., MoorthyT.V., Multi-Objective Optimization of Wear Parameters for Aluminium Matrix Composites (413/B4C) using Grey Relational Analysis, Materials todays,2018, 5:2, 7207-7216.

[5] Suryanarayana C., Mechanical Alloying and Miilling, USA,40-44,2004

[6] Ahlatçı H., Alüminyum-Silisyum Karbür Kompozitlerin MekanikÖzelliklerine ve Aşınma Davranışına Takviye Boyutunun ve Matris Bileşiminin Etkisi, Doktora Tezi, I.T.Ü, Fen Bilimleri Enstitüsü Istanbul (2003)

[7] B Manjunatha, Niranjan H.B., Satyanarayana K.G., Effect of amount of boron carbide on wear loss of Al-6061 matrix composite by Taguchi technique and Response surface analysis, Materials Science and Engineering,2018, 376,012071.

[8] Akbulut H.,Kara Y., Karbon takviyeli karbon nanotüp katkılı epoksi kompozit helisel yayların mekanik davranışları, Journal of the Faculty of Engineering and Architecture of Gazi University,2017, 32:2. 
[9] Marcelo T., Carvelho M.H., Euro PM 95 Light alloys,1995, 181-188.

[10] Firat, F. K., Eren A., Investigation of FRP Effects on Damaged Arches in Historical Masonry Structures. Journal of the Faculty of Engineering \& Architecture of Gazi University, 2015,30:4,.

[11] Kayacan M C., Delikanlı Y E., Duman B., Özsoy K., Ti6A14v toz alaşımı kullanılarak SLS ile üretilen geçişli (değişken) gözenekli numunelerin mekanik özelliklerinin incelenmesi, Journal of the Faculty of Engineering and Architecture of Gazi University,2018, 33:1 127143.

[12] Candan, E., Ahlatçı, H., Çimenoğlu, H., Abrasive wear behaviour of Al-SiC composites produced by pressure infiltration technique, Wear,2011,247, 133-138.

[13] Yörükler E.C., Mechanical Properties of Boron Carbide Particulate Rainforced Alumium Matrix Composties, Y. Lisans Tezi, ITU Fen Bilimleri Enstitüsü, 2006

[14] Chapman, T.R.; Niesz, D.E.; Fox, R.T., Fawcett, T., Wear Resistant Aluminum-BoronCarbide Cermets for Automotive Brake, Applications Wear,1999, 81-87.

[15] Zhang K.Z., Fortin A., Charette X., ChenG., Effect of titanium on microstructure and fluidity of Al-B4C composites, Journal of Materials Science,2001, 46:9,3176-3185.

[16] Arslan G., Kalemtaş A., Processing of silicon carbide-boron carbide-aluminium composites Journal of the European Ceramic Society,2009, 29,3,473-480.

[17] Arslan D., Mekanokimyasal yöntemle bor karbür sentezi ve alüminyum matrisli kompozit malzemede kullanılabilirliğinin incelenmesi, Journal of the Faculty of Engineering and Architecture of Gazi University,2013,28, 4, 875-883.

[18] Ipek R., Adhesive wear behaviour of $\mathrm{B} 4 \mathrm{C}$ and $\mathrm{SiC}$ reinforced $4147 \mathrm{Al}$ matrix composites (A1/B4C-Al/SiC), Journal of Materials Processing Technology,2005,162-163, 71-75.

[19] Akın G., Toz metalurjisi yöntemiyle alüminyum matrisli bor karbür takviyeli kompozitlerin üretilmesi ve mekanik Özelliklerinin incelenmesi, Yüksek Lisans Tezi, ITÜ Fen Bilimleri Enstitüsü, (2006)

[20] Canute X, M.C. Majumder M.C., Investigation of tribological and mechanical properties of aluminium boron carbide composites using response surface methodology and desirability analysis, Industrial Lubrication and Tribology,2018,70:2, 301-315.

[21] Topcu I., Gulsoy H.Ö., Kadıoglu N., Gulluoglu A.N., 2009. Processing and Mechanical properties of $\mathrm{B} 4 \mathrm{C}$ Reinforced Al Matrix Composites. Journal of Alloys and Compounds, 2009, 482:1-2, 516-521

[22] Gülsoy H.Ö., Bilici M K., Bozkurt Y., Salman S., Enhancing the wear properties of iron based powder metallurgy alloys by boron additions, Materials and Design,2007, 28, 22552259.

[23] Ar1k, H., Production and characterization of in situ AI4C3 reinforced aluminum-based composite produced by mechanical alloying technique, Materials and Design,2004, 25. 3140 . 